CrossMark <click for updates

Cite this: Phys. Chem. Chem. Phys., 2016, 18, 4822

Received 13th November 2015 Accepted 14th January 2016

DOI: $10.1039 / c 5 c p 06969 f$

www.rsc.org/pccp

\section{The electrooxidation-induced structural changes of gold di-superatomic molecules: $\mathrm{Au}_{23}$ vs. $\mathrm{Au}_{25} \dagger$}

\author{
Shota Matsuo, ${ }^{a}$ Seiji Yamazoe, ${ }^{\text {ab }}$ Jing-Qiang Goh, ${ }^{\text {cd }}$ Jaakko Akolacd and \\ Tatsuya Tsukuda*ab
}

\begin{abstract}
The gold cluster compounds $\mathrm{Au}_{38}\left(\mathrm{SC}_{2} \mathrm{H}_{4} \mathrm{Ph}\right)_{24}$ and $\left[\mathrm{Au}_{25}\left(\mathrm{PPh}_{3}\right)_{10}\left(\mathrm{SC}_{2} \mathrm{H}_{4} \mathrm{Ph}\right)_{5} \mathrm{Cl}_{2}\right]^{2+}$ are known to possess bi-icosahedral $\mathrm{Au}_{23}$ and $\mathrm{Au}_{25}$ cores, respectively, inside their ligand shells. These $\mathrm{Au}$ cores can be viewed as quasi-molecules composed of two $\mathrm{Au}_{13}$ superatoms sharing three and one $\mathrm{Au}^{+}$atoms, respectively. In the present work, we studied the structural changes of these gold di-superatomic molecules upon electrooxidation via spectroelectrochemical techniques, $\mathrm{X}$-ray absorption fine structure analysis, and density functional theory calculations. The $\mathrm{Au}_{23}$ core was electrochemically stable, but the $\mathrm{Au}_{25}$ core underwent irreversible structural change. This marked difference in the stability of the oxidized states is ascribed to differences in the bonding scheme of $\mathrm{Au}_{13}$ units and/or the bonding nature of the protecting ligands.
\end{abstract}

\section{Introduction}

The $\mathrm{Au}_{13}$ icosahedron is a ubiquitous structural motif that can be found in a variety of ligand-protected gold clusters, such as $\left[\mathrm{Au}_{13}\left(\mathrm{PMe}_{2} \mathrm{Ph}\right)_{10} \mathrm{Cl}_{2}\right]^{3+},{ }^{1}\left[\mathrm{Au}_{25}\left(\mathrm{SC}_{2} \mathrm{H}_{4} \mathrm{Ph}\right)_{18}\right]^{-, 2,3}\left[\mathrm{Au}_{13}\left(\mathrm{PPh}_{2} \mathrm{C}_{2} \mathrm{H}_{4^{-}}\right.\right.$ $\left.\left.\mathrm{PPh}_{2}\right)_{5} \mathrm{Cl}_{2}\right]^{3+},{ }^{4}\left[\mathrm{Au}_{19}(\mathrm{C} \equiv \mathrm{CPh})_{9}\left(\mathrm{PPh}_{2} \mathrm{NHPPh}_{2}\right)_{3}\right]^{2+},{ }^{5}$ and $\left[\mathrm{Au}_{13^{-}}\right.$ $\left.\left(\mathrm{PPh}_{2} \mathrm{C}_{2} \mathrm{H}_{4} \mathrm{PPh}_{2}\right)_{5}(\mathrm{C} \equiv \mathrm{CPh})_{2}\right]^{3+}{ }^{6}$. All of these $\mathrm{Au}_{13}$ cores formally accommodate eight valence electrons with a closed $(1 \mathrm{~S})^{2}(1 \mathrm{P})^{6}$ electronic configuration, where $\mathrm{S}$ and $\mathrm{P}$ represent orbitals with angular momentum values of 0 and 1 , respectively (Scheme 1$)^{7,8}$ Thus, the $\mathrm{Au}_{13}{ }^{5+}(8 \mathrm{e})$ core can be viewed as a stable, rare gas-like superatom. ${ }^{8}$

The $\mathrm{Au}_{13}$ core serves as the building unit for a new class of quasi-molecules known as superatomic molecules ${ }^{9,10}$ in a manner analogous to the formation of molecules from atoms. To date, two different bonding modes have been revealed by single-crystal X-ray crystallographic studies. One is a facesharing mode found in the $\mathrm{Au}_{23}{ }^{9+}(14 \mathrm{e})$ core of $\mathrm{Au}_{38}(\mathrm{SR})_{24} \cdot{ }^{11}$ The other is a vertex-sharing mode found in the $\mathrm{Au}_{25}{ }^{9+}(16 \mathrm{e})$, $\mathrm{Au}_{37}{ }^{13+}(24 \mathrm{e})$, and $\mathrm{Au}_{60}{ }^{2++}(40 \mathrm{e})$ cores of $\left[\mathrm{Au}_{25}\left(\mathrm{PR}_{3}\right)_{10}\left(\mathrm{SR}^{\prime}\right)_{5} \mathrm{Cl}_{2}\right]^{2+},{ }^{2+}$ $\left[\mathrm{Au}_{37}\left(\mathrm{PR}_{3}\right)_{10}\left(\mathrm{SR}^{\prime}\right)_{10} \mathrm{Cl}_{2}\right]^{+},{ }^{13}$ and $\left[\mathrm{Au}_{60} \mathrm{Se}_{2}\left(\mathrm{PR}_{3}\right)_{10}\left(\mathrm{SeR}^{\prime}\right)_{15}\right]^{+14}$, respectively. A recent computational study suggests that the $\mathrm{Au}_{23}{ }^{9+}$ core

\footnotetext{
${ }^{a}$ Department of Chemistry, School of Science, The University of Tokyo, 7-3-1 Hongo, Bunkyo-ku, Tokyo 113-o033, Japan. E-mail: tsukuda@chem.s.u-tokyo.ac.jp

${ }^{b}$ Elements Strategy Initiative for Catalysts and Batteries (ESICB), Kyoto University, Katsura, Kyoto 615-8520, Japan

${ }^{c}$ Department of Physics, Tampere University of Technology, P.O. Box 692, FI-33101 Tampere, Finland

${ }^{d}$ COMP Centre of Excellence, Department of Applied Physics, Aalto University, FI-00076 Aalto, Finland

$\dagger$ Electronic supplementary information (ESI) available. See DOI: 10.1039/ c5cp06969f
}

can be viewed as a dimer of halogen-like $\mathrm{Au}_{13}{ }^{6+}(7 \mathrm{e})$ superatoms formed by sharing three $\mathrm{Au}^{+}$atoms (Scheme 1a): ${ }^{9}$

$$
\mathrm{Au}_{23}{ }^{9+}(14 \mathrm{e})=2 \times \mathrm{Au}_{13}{ }^{6+}(7 \mathrm{e})-3 \mathrm{Au}^{+}
$$

The electronic configuration of $\mathrm{Au}_{23}{ }^{9+}(14 \mathrm{e})$ may be described as $(1 \sigma)^{2}\left(1 \sigma^{*}\right)^{2}(1 \pi)^{4}(2 \sigma)^{2}\left(1 \pi^{*}\right)^{4}$. The $1 \sigma$ and $1 \sigma^{*}$ orbitals are constructed from the $1 \mathrm{~S}$ superatomic orbitals of $\mathrm{Au}_{13}{ }^{6+}(7 \mathrm{e})$,
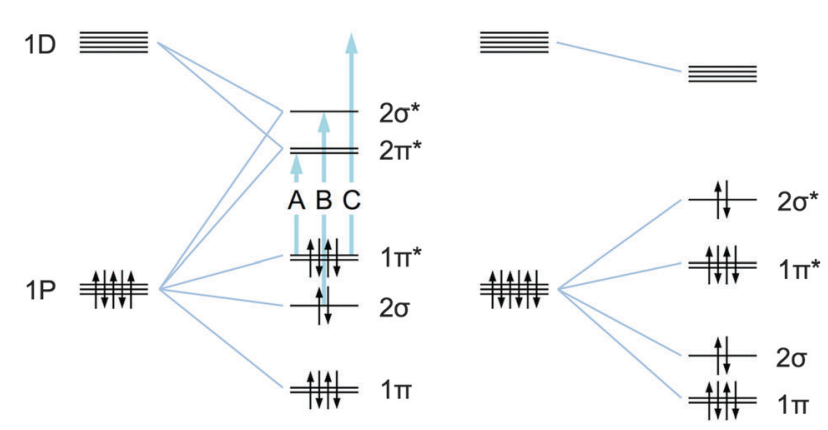

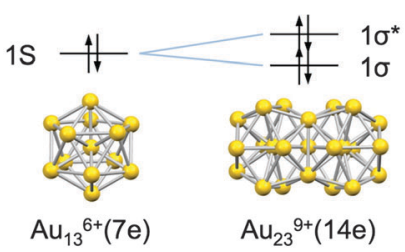

(a)

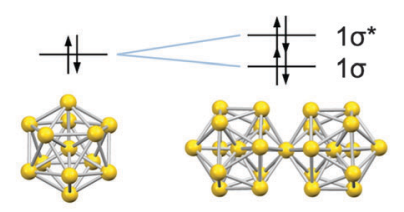

$\mathrm{Au}_{13}{ }^{5+}(8 \mathrm{e})$
$\mathrm{Au}_{25}{ }^{9+}(16 \mathrm{e})$
Scheme 1 Schematic representation of the bonding scheme for (a) $\mathrm{Au}_{23}{ }^{9+}(14 \mathrm{e})$ and (b) $\mathrm{Au}_{25}{ }^{9+}(16 \mathrm{e})$ from their superatomic units (ref. 18 and 19). The energy scales are arbitrary and the energy splitting of superatomic orbitals (ref. 20 and 21) is ignored. Optical transitions A, B, and C correspond to the peaks in the optical spectrum (Fig. 1a). 
whereas the $1 \pi, 2 \sigma$, and $1 \pi^{*}$ orbitals result from the $1 \mathrm{P}$ superatomic orbitals of $\mathrm{Au}_{13}{ }^{6+}(7 \mathrm{e})$. This super valence bond model can also be applied to bonding in the vertex-sharing $\mathrm{Au}_{25}{ }^{9+}$, which may be considered as a dimer generated by rare gas-like $\mathrm{Au}_{13}{ }^{5+}(8 \mathrm{e})$ superatoms sharing an $\mathrm{Au}^{+}$atom (Scheme 1b): ${ }^{12,15-17}$

$$
\mathrm{Au}_{25}{ }^{9+}(16 \mathrm{e})=2 \times \mathrm{Au}_{13}{ }^{5+}(8 \mathrm{e})-\mathrm{Au}^{+} .
$$

The formal bond orders in $\mathrm{Au}_{23}{ }^{9+}$ and $\mathrm{Au}_{25}{ }^{9+}$ can be calculated to be one and zero, respectively.

In terms of the bonding scheme, the $\mathrm{Au}_{23}{ }^{9+}(14 \mathrm{e})$ and $\mathrm{Au}_{25}{ }^{9+}(16 \mathrm{e})$ cores correspond to an $\mathrm{F}_{2}$ molecule and a van der Waals dimer of $\mathrm{Ne}$, respectively. These di-superatomic molecules, thus, provide an interesting opportunity to study similarities and differences of the fundamental properties between conventional molecules and superatomic molecules. This study aims to compare the structural changes of superatomic molecules induced by electrooxidation with those of conventional molecules by ionization. In the case of molecules, the bond distance is the unique structure parameter that can be changed. For example, the F-F bond of $F_{2}$ is shortened from 1.44 to $1.33 \AA$ upon ionization owing to the removal of an electron from the highest occupied molecular orbital (HOMO) of anti-bonding nature. ${ }^{22}$ The internuclear distance of $\mathrm{Ne}_{2}$ is significantly reduced from 3.09 to $1.7 \AA$ upon ionization owing to the charge-resonance stabilization in $\mathrm{Ne}_{2}{ }^{+23}$ In the case of superatomic molecules, the structural change of superatomic units themselves may be induced in addition to the elongation/reduction of their distance. In the present study, we investigated how the geometric structures of the $\mathrm{Au}_{23}{ }^{9+}$ and $\mathrm{Au}_{25}{ }^{9+}$ cores are altered upon electrooxidation using spectroelectrochemical methods, ${ }^{24} \mathrm{X}$-ray absorption fine structure (XAFS) analysis and density functional theory (DFT) calculations.

\section{Experimental and computational methods}

\section{Synthesis of samples}

All of the chemicals used in this study were commercially available. Samples of $\mathrm{Au}_{38}\left(\mathrm{SC}_{2} \mathrm{H}_{4} \mathrm{Ph}\right)_{24}\left(\mathbf{1}^{0}\right)$ and $\left[\mathrm{Au}_{25}\left(\mathrm{PPh}_{3}\right)_{10}\left(\mathrm{SC}_{2} \mathrm{H}_{4} \mathrm{Ph}\right)_{5} \mathrm{Cl}_{2}\right]^{2+}$ $\left(2^{2+}\right)$ were synthesized according to literature procedures, but with slight modifications. ${ }^{12,25,26}$ The details of the syntheses are described in the ESI. $\dagger$ Successful synthesis of both compounds was confirmed by matrix-assisted laser desorption ionization (MALDI) mass spectrometry and optical absorption spectroscopy.

\section{Electrochemical measurements}

Cyclic voltammetry (CV) and differential pulse voltammetry (DPV) of 1 and $\mathbf{2}$ were performed using an electrochemical analyzer (BAS, ALS720B) at room temperature under an Ar atmosphere. The electrolyte solution used for these measurements was $0.1 \mathrm{M}$ tetrabutylammonium hexafluorophosphate $\left(\mathrm{NBu}_{4} \mathrm{PF}_{6}\right)$ in 1,2-dichloroethane (DCE) purged with Ar. The working, reference, and counter electrodes were a $1 \mathrm{~mm}$ glassy carbon disk, $\mathrm{Ag} / \mathrm{AgNO}$ $\left(-0.21 \mathrm{~V}\right.$ vs. $\left.\mathrm{Fc} / \mathrm{Fc}^{+}\right)$, and a Pt wire, respectively. The potential scan was initiated at open circuit potential $(0.01$ and $-0.27 \mathrm{~V}$ for 1 and 2, respectively) in the negative direction.
The optical absorption spectra of $\mathbf{1}$ and $\mathbf{2}$ in the UV-vis-NIR region were recorded under electrochemical redox conditions. These spectroelectrochemical measurements were conducted in a DCE solution containing $0.1 \mathrm{M} \mathrm{NBu}_{4} \mathrm{PF}_{6}$ that was purged with Ar prior to measurements using an electrochemical analyzer (BAS, ALS720B) and two spectrophotometers (Jasco, V-670 for 1 and Agilent, Agilent 8453 for 2 ). A quartz cell (1 mm width) was used for spectroelectrochemistry. The working, reference, and counter electrodes were an optically transparent Pt mesh electrode, an $\mathrm{Ag} / \mathrm{AgNO}_{3}$ electrode, and a $\mathrm{Pt}$ wire electrode, respectively. The Pt mesh electrode was set in the light path of the spectroelectrochemical cell.

\section{Bulk electrolysis}

The bulk electrolysis of $\mathbf{2}$ was carried out in a spectroelectrochemical $10 \mathrm{~mm}$ quartz cell (HX-701Y, Hokuto Denko) with an electrochemical analyzer (BAS, ALS720B). The working, reference, and counter electrodes were a Pt mesh electrode, an $\mathrm{Ag} / \mathrm{AgNO}$ electrode, and a Pt coil electrode, respectively. The electrolysis was conducted in a DCE solution containing $0.1 \mathrm{M} \mathrm{NBu}_{4} \mathrm{PF}_{6}$, which was purged with Ar prior to measurements. The completion of the bulk electrolysis was established by optical absorption spectroscopy.

\section{XAFS spectroscopy}

Au $\mathrm{L}_{3}$-edge XAFS measurements were performed on the BL01B1 beamline at the SPring-8 facility of the Japan Synchrotron Radiation Institute (proposal nos. 2012B1986, 2014B1430, and 2014A1680). A Si(311) two-crystal monochromator was used for the incident beam and all spectra were recorded in transmission mode using ion chambers as the $I_{0}$ and $I$ detectors. Samples of 2 diluted with boron nitride and 2 electrolyzed and diluted with $\mathrm{NBu}_{4} \mathrm{PF}_{6}$ were placed in the cryostat for measurements at 8 or $10 \mathrm{~K}$. Energy scale was calibrated using $\mathrm{Cu}$ foil and data analysis was carried out employing the REX2000 Ver. 2.5.92 software package (Rigaku Co.). The $k^{3}$-weighted $\chi$ spectra in the $k$ range of 3.0-16.0 $\AA^{-1}$ were Fourier-transformed (FT) into $r$-space. The curve fitting analysis was performed for $\mathrm{Au}-\mathrm{S}(\mathrm{P}, \mathrm{Cl})$ and $\mathrm{Au}-\mathrm{Au}$ bonds over the $r$ range of 1.5-3.2 $\AA$. In the curve fitting analysis, the phase shifts and back-scattering amplitude functions for the $\mathrm{Au}-\mathrm{S}$ and $\mathrm{Au}-\mathrm{Au}$ bonds were extracted from $\mathrm{Au}_{2} \mathrm{~S}$ (ICSD\#78718) and Au metal (ICSD\#44362), respectively, using the FEFF8 program. ${ }^{27}$ The phase shifts and back-scattering amplitude functions of $\mathrm{Au}-\mathrm{S}$ were used for those of $\mathrm{Au}-\mathrm{P}$ and $\mathrm{Au}-\mathrm{Cl}$ because the electron densities of $\mathrm{P}$ and $\mathrm{Cl}$ atoms are close to that of $\mathrm{S}$ atom.

\section{Transmission electron microscopy}

Transmission electron microscopy (TEM) images were recorded by using a Hitachi HF-2000 microscope operated at $200 \mathrm{kV}$. A dispersion of the electrooxidized sample of 2 was dropped onto a carbon-coated copper grid. The sample grid was dried at room temperature in air.

\section{Computational methods}

The GPAW software, ${ }^{28}$ a projector-augmented wave (PAW) and real-space grid DFT package, was employed to inspect the redox 
behavior of 1 and 2. Structural optimizations were performed in the gas phase environment with consideration of the full ligands, until the residual forces acting on the atoms reached $0.05 \mathrm{eV} \AA^{-1}$ or below. The spin-polarized DFT simulations were performed with a real-space grid spacing of $0.2 \AA$ and included the scalar relativistic effect for PAW setups. Linear response time-dependent DFT based on Casida's formulation ${ }^{29}$ was employed to analyze the optical absorption spectra of $2^{2+}$ and $2^{3+}$. All the calculations in this work adopted the generalized gradient-corrected exchange-correlation functional developed by Perdew, Burke and Ernzerhof (PBE). ${ }^{30}$

\section{Results and discussion}

\section{Redox behavior of $\mathrm{Au}_{38}\left(\mathrm{SC}_{2} \mathrm{H}_{4} \mathrm{Ph}\right)_{24}$}

The successful synthesis of $\mathrm{Au}_{38}\left(\mathrm{SC}_{2} \mathrm{H}_{4} \mathrm{Ph}\right)_{24}\left(\mathbf{1}^{0}\right)$ was confirmed by MALDI mass spectrometry (Fig. S1, ESI $\dagger$ ). An intense peak at $m / z=1.078 \times 10^{4}$ was assigned to intact $\mathrm{Au}_{38}\left(\mathrm{SC}_{2} \mathrm{H}_{4} \mathrm{Ph}\right)_{24}$, whereas a smaller peak at $m / z=9.33 \times 10^{3}$ was attributed to a fragment with the formula $\mathrm{Au}_{34}\left(\mathrm{SC}_{2} \mathrm{H}_{4} \mathrm{Ph}\right)_{19} \mathrm{~S} .^{25}$ The optical absorption spectrum of $\mathbf{1}^{0}$ (Fig. 1a) shows distinct peaks at 1.18 (peak A), 1.65 (peak B), 1.97 (peak C), 2.39, and $2.57 \mathrm{eV}$, in agreement with previously reported data. ${ }^{31}$ The peaks $\mathrm{A}, \mathrm{B}$ and $\mathrm{C}$ have been theoretically assigned to the electronic transitions $\operatorname{HOMO}\left(1 \pi^{*}\right) \rightarrow \operatorname{LUMO}\left(2 \pi^{*}\right), \mathrm{HOMO}-1(2 \sigma) \rightarrow \operatorname{LUMO}+1\left(2 \sigma^{*}\right)$, and $\operatorname{HOMO}\left(1 \pi^{*}\right) \rightarrow \mathrm{LUMO}+3$, respectively (Scheme $\left.1 \mathrm{a}\right) .{ }^{18}$

Fig. $1 \mathrm{~b}$ shows the $\mathrm{CV}$ curves of $\mathbf{1}^{0}$ recorded at different scan rates; an arrow indicates the open circuit potential. These plots exhibit two pairs of redox peaks for the $0 /+1$ and $+1 /+2$ couples at the same voltages, regardless of the scan rates. The peak-to-peak separations of the two couples are 58 and $61 \mathrm{mV}$, respectively, at a scan rate of $100 \mathrm{mV} \mathrm{s}^{-1} .^{32}$ This reversible behavior indicates that 1 and its oxidized forms $\mathbf{1}^{1+}$ and $\mathbf{1}^{2+}$ are stable in the electrolyte solution. The formal potentials of the redox couples $\mathbf{1}^{0 / 1+}$ and $\mathbf{1}^{1+/ 2+}$ were determined to be 0.07 and $0.32 \mathrm{~V}$, respectively. These values are smaller by several tens of meV than reported values obtained

(a)

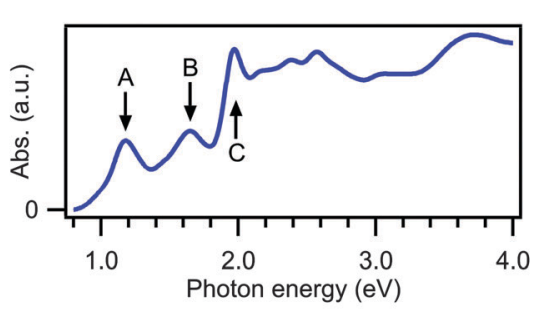

(b)

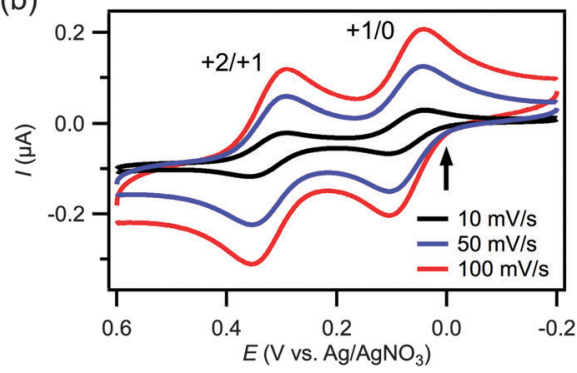

Fig. 1 (a) Optical absorption spectrum and (b) CV curves of $\mathbf{1}^{\circ}$. from CV using acetonitrile: benzene (1:1) as a solvent of the electrolyte solution. ${ }^{33}$ Based on these results, it is evident that $\mathbf{1}^{1+}$ and $\mathbf{1}^{2+}$ can be synthesized by the electrolysis of $\mathbf{1}^{0}$ at 0.20 and $0.60 \mathrm{~V}$, respectively.

The optical absorption spectra of $\mathbf{1}^{0}, \mathbf{1}^{1+}$, and $\mathbf{1}^{2+}$ are displayed in Fig. 2a. The positions of peaks A, B, and $\mathrm{C}$ of $\mathbf{1}^{0}$ (Fig. 1a) are unchanged following electrolysis whereas the intensities of these peaks change depending on the charge states of $\mathbf{1}$. The intensities of peaks $\mathrm{A}$ and $\mathrm{C}$ decreased with oxidation. The reduction of the peak intensities upon oxidation to +1 and +2 is ascribed to the reduced probability of transition from the $\operatorname{HOMO}\left(1 \pi^{*}\right)$ orbital from which the electron(s) is/are removed. In contrast, the intensity of peak B did not change upon oxidation. This behavior can be understood by considering that the $\operatorname{HOMO}\left(1 \pi^{*}\right)$ orbital is not involved in the optical transition. Interestingly, the absorbance of the valley between peaks $\mathrm{B}$ and $\mathrm{C}$ increased upon oxidation, suggesting that a new optical transition became accessible in the oxidized state. According to a previously reported theoretical study, ${ }^{18}$ the increased absorbance at $1.8 \mathrm{eV}$ can be attributed to an optical transition to the $\operatorname{HOMO}\left(1 \pi^{*}\right)$ orbital, in which one or more holes are created by oxidation.

Fig. $2 \mathrm{~b}$ shows the spectra obtained by subtracting the spectrum of $\mathbf{1}^{0}$ from those of $\mathbf{1}^{1+}$ and $\mathbf{1}^{2+}$. The peak positions evidently did not change upon oxidation, indicating that the energy levels of the superatomic orbitals of $\mathbf{1}$ do not change regardless of the charge state. Given that the electronic structures of small clusters are sensitive to slight difference in the geometric structure, ${ }^{34}$ this result indicates that the geometric structure of $\mathbf{1}$ is not changed appreciably by the redox reactions. Namely, the bond length between the $\mathrm{Au}_{13}$ units within 1 was not changed even after the formal bond order is increased from 1 to 2 . This behavior is in sharp contrast to that of $\mathrm{F}_{2}$, a molecular analogue of $\mathrm{Au}_{23}{ }^{9+}$, since it is known that the $\mathrm{F}-\mathrm{F}$ bond length in $\mathrm{F}_{2}{ }^{+}(1.33 \AA)$ is shorter than that in $\mathrm{F}_{2}(1.44 \AA) .{ }^{22}$ The negligible structural change of $\mathrm{Au}_{23}{ }^{9+}$,
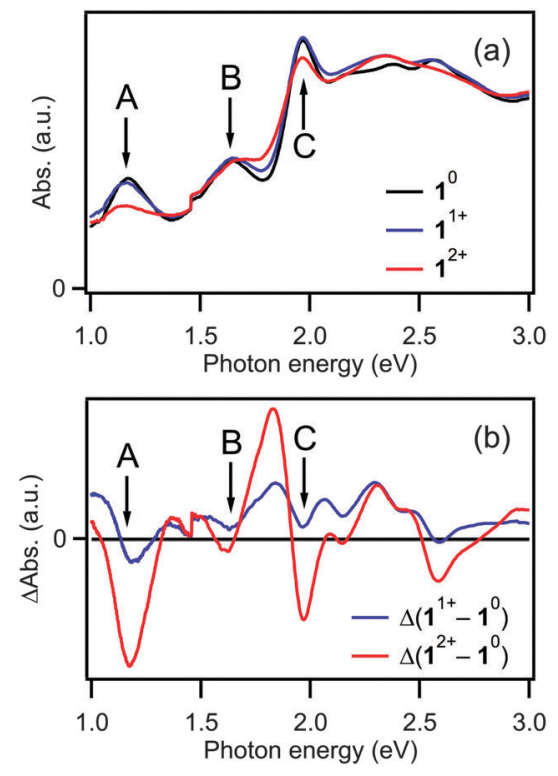

Fig. 2 (a) Optical absorption spectra of $\mathbf{1}^{0}, \mathbf{1}^{1+}$, and $\mathbf{1}^{2+}$ and (b) spectra of $1^{1+}$ and $1^{2+}$ following subtraction of the spectrum of $1^{0}$. 
even after 2-electron oxidation, thus demonstrates the structural rigidity of the face-sharing bi-icosahedral $\mathrm{Au}_{23}$.

Furthermore, the DFT structural optimizations of $\mathbf{1}^{0}$ and $\mathbf{1}^{2+}$ support this finding showing that the bond distances of core atoms do not change significantly at different charge states (Fig. S3 and Table S1, ESI $\dagger$ ). One of the $\operatorname{HOMO}\left(1 \pi^{*}\right)$ orbitals in $\mathbf{1}^{0}$ is promoted to the LUMO orbital in $\mathbf{1}^{2+}$, but the HOMO orbitals of these structures still retain the same symmetry of $1 \pi^{*}$ (Fig. S4, ESI $\dagger$ ). Hence, there is no distinctive structural effect induced by the electronic factor. The rigidity of $\mathrm{Au}_{23}{ }^{9+}$ may partly arise from the protection by the rigid Au-SR oligomers with different lengths: especially three -SR-Au-SR- "staples" bridge across the waist of two $\mathrm{Au}_{13}$ icosahedra. ${ }^{35}$

\section{Redox behavior of $\left[\mathrm{Au}_{25}\left(\mathrm{PPh}_{3}\right)_{10}\left(\mathrm{SC}_{2} \mathrm{H}_{4} \mathrm{Ph}\right)_{5} \mathrm{Cl}_{2}\right]^{2+}$}

The synthesis of $\left[\mathrm{Au}_{25}\left(\mathrm{PPh}_{3}\right)_{10}\left(\mathrm{SC}_{2} \mathrm{H}_{4} \mathrm{Ph}\right)_{5} \mathrm{Cl}_{2}\right]^{2+}\left(2^{2+}\right)$ was confirmed by optical spectroscopy (Fig. 3a). The spectrum shows distinct peaks at $1.84,2.98,3.30$, and $3.76 \mathrm{eV}$, which reproduces the reported data. ${ }^{12,36}$ The CV curves of $2^{2+}$ shown in Fig. $3 \mathrm{~b}$ exhibit irreversible waves in both the oxidative and reductive potential ranges. This result indicates that cluster $2^{2+}$ is unstable upon one-electron oxidation.

Fig. 4a presents the optical absorption spectra obtained during one-electron oxidation of $2^{2+}$ at $0.60 \mathrm{~V}$. The spectral profile changes with time while exhibiting three isosbestic points, as indicated by arrows. The peak at $1.84 \mathrm{eV}$ drops in intensity and the optical gap is reduced during the electrooxidation reactions. This result implies that the electrooxidation of $2^{2+}$ yielded a certain product having less structured absorption spectrum than $2^{2+}$.

In order to gain insight into the electronic structures of the one-electron oxidation product, we attempted to extract its optical spectrum by assuming that $2^{2+}$ is converted to a single species upon electrooxidation. Namely, we assume that the spectra in Fig. 4a represent a linear combination of the spectra of unoxidized $2^{2+}$ and the oxidation product. Because the population
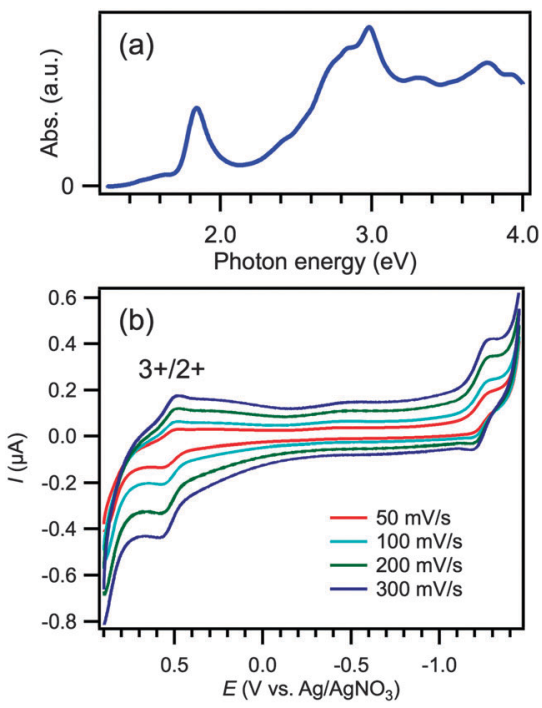

Fig. 3 (a) Optical absorption spectrum and (b) CV curves of $\mathbf{2}^{2+}$.
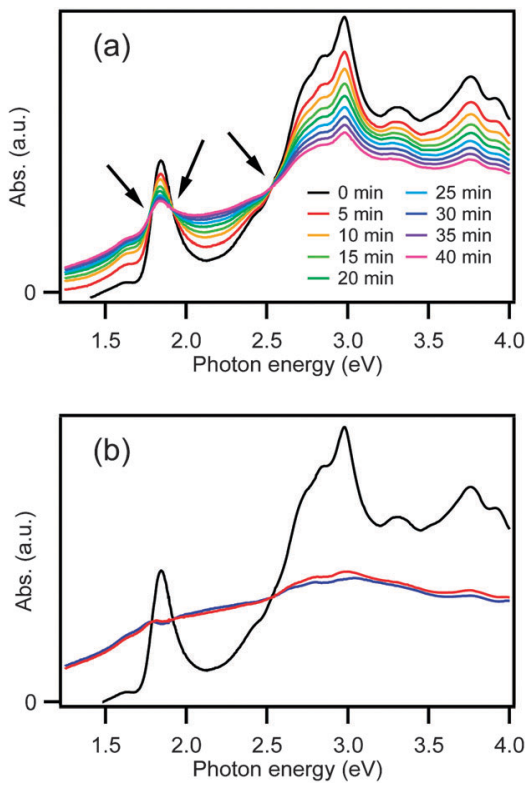

Fig. 4 (a) Optical absorption spectra of $\mathbf{2}^{2+}$ following electrolysis at $0.60 \mathrm{~V}$. (b) Deconvoluted spectra of oxidized species assuming that the spectrum after 40 min contains $20 \%$ (red) and $24 \%$ (blue) of $\mathbf{2}^{2+}$. The black curve shows the spectrum of $\mathbf{2}^{2+}$ for reference.

of unoxidized $2^{2+}$ at a certain time is unknown, we further assume that the oxidation product does not have sharp peaks at the same position with those of $2^{2+}$. The optical spectra of the oxidation product extracted based on these assumptions are shown in Fig. 4b. Although there is an ambiguity in the spectral profile depending on the assumed concentration of unoxidized $2^{2+}$, we can conclude that the oxidation product is less structured as compared to $2^{2+}$ and optical onset is shifted to lower energy.

DFT calculations were carried out to study the geometric structure and optical properties of the one-electron oxidation product. Structural optimization of $2^{3+}$ starting from vertexsharing biicosahedral cores with eclipsed and staggered configurations (Fig. S5, ESI $\dagger$ ) both yielded the eclipsed motif, which is similar to that of $2^{2+}$ (Fig. 5a). The optimization results do not suggest that a staggered (twisted bi-icosahedral core) ${ }^{37}$ configuration is preferred for $2^{3+}$, upon oxidation of $2^{2+}$. Since the HOMO of $2^{2+}$ has anti-bonding nature according to the previous theoretical calculations (Scheme 1b), ${ }^{15,17}$ one would expect that the distance between the two $\mathrm{Au}_{13}$ units to become smaller upon oxidation. In contrast to the prediction from Scheme $1 \mathrm{~b}$, the distance between the two $\mathrm{Au}_{13}$ units is slightly increased upon oxidation: the average distance between the nearest neighboring $\mathrm{Au}$ atoms between the $\mathrm{Au}_{13}$ units are $3.23 \pm 0.018$ and $3.27 \pm 0.015 \AA$ for $2^{2+}$ and $2^{3+}$, respectively (Fig. 5a). This unexpected trend is due to the fact that the HOMO of $2^{2+}$ obtained by the present calculation has bonding nature (Fig. S6, ESI $\dagger$ ). Inspection of the shape of the HOMO suggests that it is constructed via bonding interaction between 1P superatomic orbitals of $\mathrm{Au}_{13}$ moieties. Based on Scheme $1 \mathrm{~b}$, the HOMO of $2^{2+}$ corresponds now to a $2 \sigma$ state. Meanwhile, both the HOMO-1 and HOMO -2 correspond to $1 \pi^{*}$ states; and the HOMO-3 refers to a $2 \sigma^{*}$ state (Fig. S6, ESI $\dagger$ ). Therefore, the ordering of the energetic 
(a)

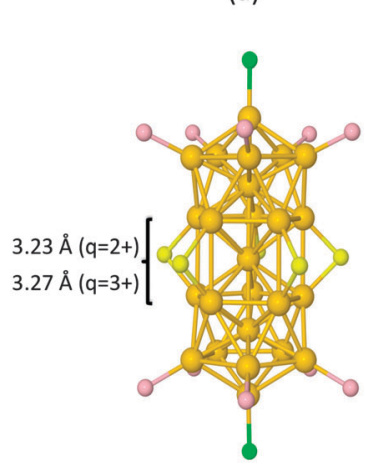

(b)

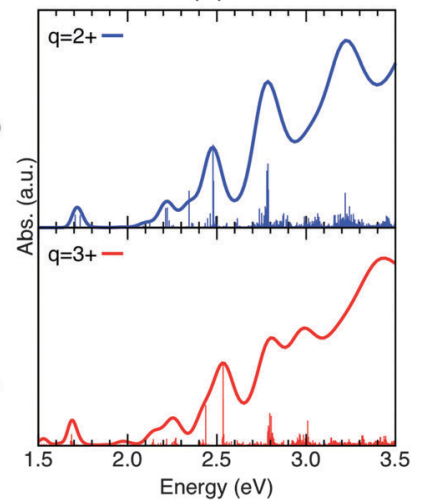

Fig. 5 (a) Optimized core structures and (b) optical absorption spectra of $\mathbf{2}^{2+}$ and $\mathbf{2}^{3+}$. For simplicity, the ligands are omitted. The individual transition values have been multiplied by a factor of 20 , and the full range of optical absorption spectra are available in Fig. S7 (ESI $\dagger$ ). There is no significant change between the core structures optimized in different charge states, with a slight increment for distances between the nearest neighboring Au atoms of the $\mathrm{Au}_{13}$ moieties.

states of HOMO and HOMO-3 has been interchanged. We consider this as a ligand effect: the energetically closely spaced orbitals, which are of superatomic $1 \mathrm{P}$ character, are sensitive to the influence of localized p-orbital states of individual sulfur atoms at the cluster waistline, and this lowers the energy of the $2 \sigma^{*}$ state.

Fig. 5b shows the calculated optical absorption spectra of $2^{2+}$ and $2^{3+}$. The calculated spectrum of $2^{2+}$ reproduces well (a)

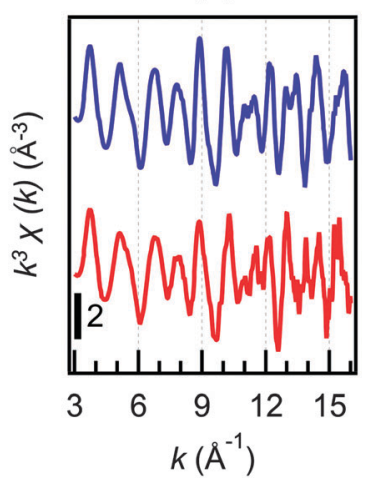

(b)

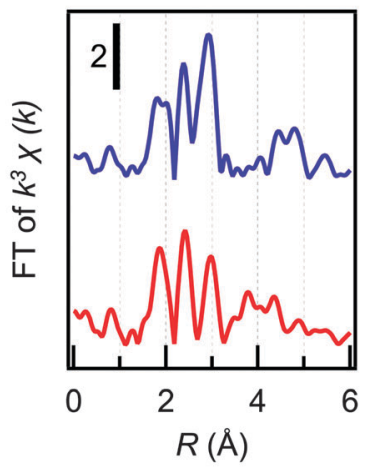

Fig. 6 (a) Au $\mathrm{L}_{3}$-edge EXAFS oscillations and (b) FT spectra of $\mathbf{2}^{2+}$ (blue) and the one-electron oxidation product (red). characteristic features of the experimental spectra (Fig. 3a). The spectrum of $2^{3+}$ appears to be similar to that of $2^{2+}$. Especially, the characteristic peak at $\sim 1.7 \mathrm{eV}$ for $2^{2+}$ is still present for $2^{3+}$ (odd number of electrons, with spin-polarization), which is inconsistent with the experimental observation (Fig. 5b). This contradiction suggests that oxidized form $2^{3+}$ is not stable in solution and is transformed into another structure or structures.

The electrooxidation sample of $2^{2+}$ was examined by TEM. In the TEM images (Fig. S8, ESI $\dagger$ ), only Au clusters smaller than $2 \mathrm{~nm}$ were observed although the sample contained unoxidized $2^{2+}$. This observation and the absence of a surface plasmon resonance band in the oxidized sample (Fig. 4b) suggest that aggregation of $2^{2+}$ is not induced upon oxidation. The oxidation product obtained after bulk electrolysis of $2^{2+}$ was further examined using XAFS. Fig. 6 shows the $\mathrm{Au} \mathrm{L}_{3}$-edge extended $\mathrm{X}$-ray absorption fine structure (EXAFS) oscillations and FT-EXAFS spectra of $2^{2+}$ and the oxidation product. The results of the EXAFS analysis are summarized in Table 1 . From these data, it is evident that the coordination numbers of the $\mathrm{Au}-\mathrm{Au}$ and $\mathrm{Au}$-ligand bonds did not change appreciably upon electrooxidation.

The experimental and theoretical results reported above suggest that $\mathrm{Au}_{25}{ }^{9+}$ with the vertex-sharing biicosahedral motif undergoes irreversible structural change upon oxidation. It is reported that phosphine-protected $\mathrm{Au}$ clusters such as $\left[\mathrm{Au}_{11}\left(\mathrm{PPh}_{3}\right)_{8} \mathrm{Cl}_{2}\right]^{+}$are electrochemically unstable, ${ }^{38}$ whereas thiolate-protected Au clusters such as $\left[\mathrm{Au}_{25}(\mathrm{SR})_{18}\right]^{-}$are electrochemically stable. ${ }^{38,39}$ Thus, difference in the electrochemical instability between $\mathrm{Au}_{23}{ }^{9+}$ and $\mathrm{Au}_{25}{ }^{9+}$ superatomic molecules may be associated with that in the protecting ligands. The $\mathrm{Au}_{23}{ }^{9+}$ core is protected by three -SR-Au-SR- and six -SR-(Au-SR $)_{2}$ - oligomers, whereas the $\mathrm{Au}_{25}{ }^{9+}$ core is protected by five $\mathrm{RS}$, ten $\mathrm{PR}_{3}$ and two halides. One possible pathway is the isomerization of the $\mathrm{Au}_{25}$ core induced by the release of the phosphine ligand upon electrooxidation. Such electrochemically irreversible structural isomerization has been observed in $\left[\mathrm{Au}_{8}\left(\mathrm{Ph}_{2} \mathrm{P}\left(\mathrm{CH}_{2}\right)_{3} \mathrm{PPh}_{2}\right)_{4}\right]^{n+}(n=2$ and 4$){ }^{40}$

\section{Conclusions}

The structural changes of $\mathrm{Au}_{38}\left(\mathrm{SC}_{2} \mathrm{H}_{4} \mathrm{Ph}\right)_{24}$ and $\left[\mathrm{Au}_{25}\left(\mathrm{PPh}_{3}\right)_{10^{-}}\right.$ $\left.\left(\mathrm{SC}_{2} \mathrm{H}_{4} \mathrm{Ph}\right)_{5} \mathrm{Cl}_{2}\right]^{2+}$ upon electrooxidation were studied by spectroelectrochemical and XAFS measurements and DFT calculations. The face-sharing $\mathrm{Au}_{23}{ }^{9+}$ biicosahedron protected by $\mathrm{Au}-\mathrm{SR}$ oligomers retains the structure upon oxidation, indicating that oxidation-induced geometric relaxation is negligibly small in

Table 1 Fitted EXAFS parameters for the electrooxidation product

\begin{tabular}{|c|c|c|c|c|c|}
\hline Sample & Atom $^{a}$ & C.N. ${ }^{b}$ & $r^{c}(\AA)$ & D.W. ${ }^{d}$ & $R^{e}(\%)$ \\
\hline $2^{2+}$ & $\begin{array}{l}\mathrm{S}(\mathrm{P}, \mathrm{Cl}) \\
\mathrm{Au} 1 \\
\mathrm{Au} 2\end{array}$ & $\begin{array}{l}1.1(2) \\
2.4(1.2) \\
4.2(7)\end{array}$ & $\begin{array}{l}2.324(11) \\
2.744(3) \\
2.875(3)\end{array}$ & $\begin{array}{l}0.0061(27) \\
0.0045(7) \\
0.0050(5)\end{array}$ & 9.9 \\
\hline One-electron oxidation product & $\begin{array}{l}\mathrm{S}(\mathrm{P}, \mathrm{Cl}) \\
\mathrm{Au} 1 \\
\mathrm{Au} 2\end{array}$ & $\begin{array}{l}0.9(1) \\
1.5(2) \\
4.4(5)\end{array}$ & $\begin{array}{l}2.306(4) \\
2.727(20) \\
2.860(22)\end{array}$ & $\begin{array}{l}0.0040(15) \\
0.0040(10) \\
0.0076(12)\end{array}$ & 8.9 \\
\hline
\end{tabular}

${ }^{a}$ Bonding atom. ${ }^{b}$ Coordination number. ${ }^{c}$ Bond length. ${ }^{d}$ Debye-Waller factor. ${ }^{e} R$ factor. 
contrast to the corresponding molecule $\mathrm{F}_{2}$. In contrast, the vertex-sharing $\mathrm{Au}_{25}{ }^{9+}$ biicosahedron protected by thiolates, phosphines and halides underwent irreversible structural change. This electrochemical instability is ascribed to the bonding scheme between two $\mathrm{Au}_{13}$ units and/or the bonding nature of the protecting ligands.

\section{Acknowledgements}

We thank Prof. Hiroshi Nishihara (The University of Tokyo) for providing us with access to the TEM apparatus. This research was financially supported by the Elements Strategy Initiative for Catalysis \& Batteries (ESICB) and by a Grant-in-Aid for Scientific Research (no. 26248003) from the Ministry of Education, Culture, Sports, Science, and Technology (MEXT) of Japan. Financial support from the Centres of Excellence Program (Project 284621) by the Academy of Finland and the graduate student scholarship by Magnus Ehrnrooth foundation are gratefully acknowledged. Computational resources were provided by CSC - the IT Center for Science Ltd Espoo, Finland.

\section{Notes and references}

1 C. E. Briant, B. R. C. Theobald, J. W. White, L. K. Bell, D. M. P. Mingos and A. J. Welch, J. Chem. Soc., Chem. Commun., 1981, 5, 201.

2 M. W. Heaven, A. Dass, P. S. White, K. M. Holt and R. W. Murray, J. Am. Chem. Soc., 2008, 130, 3754.

3 M. Zhu, C. M. Aikens, F. J. Hollander, G. C. Schatz and R. Jin, J. Am. Chem. Soc., 2008, 130, 5883.

4 Y. Shichibu and K. Konishi, Small, 2010, 6, 1216.

5 X.-K. Wan, Q. Tang, S.-F. Yuan, D.-e. Jiang and Q.-M. Wang, J. Am. Chem. Soc., 2015, 137, 652.

6 M. Sugiuchi, Y. Shichibu, T. Nakanishi, Y. Hasegawa and K. Konishi, Chem. Commun., 2015, 51, 13519.

7 J. Akola, M. Walter, R. L. Whetten, H. Häkkinen and H. Grönbeck, J. Am. Chem. Soc., 2008, 130, 3756.

8 M. Walter, J. Akola, O. Lopez-Acevedo, P. D. Jadzinsky, G. Calero, C. J. Ackerson, R. L. Whetten, H. Grönbeck and H. Häkkinen, Proc. Natl. Acad. Sci. U. S. A., 2008, 105, 9157.

9 L. Cheng, C. Ren, J. Zhang and X. Yang, Nanoscale, 2013, $5,1475$.

10 J. Nishigaki, K. Koyasu and T. Tsukuda, Chem. Rec., 2014, 14, 897.

11 H. Qian, W. T. Eckenhoff, Y. Zhu, T. Pintauer and R. Jin, J. Am. Chem. Soc., 2010, 132, 8280.

12 Y. Shichibu, Y. Negishi, T. Watanabe, N. K. Chaki, H. Kawaguchi and T. Tsukuda, J. Phys. Chem. C, 2007, 111, 7845.

13 R. Jin, C. Liu, S. Zhao, A. Das, H. Xing, C. Gayathri, Y. Xing, N. L. Rosi, R. R. Gil and R. Jin, ACS Nano, 2015, 9, 8530.

14 Y. Song, F. Fu, J. Zhang, J. Chai, X. Kang, P. Li, S. Li, H. Zhou and M. Zhu, Angew. Chem., Int. Ed., 2015, 54, 8430.

15 K. Nobusada and T. Iwasa, J. Phys. Chem. C, 2007, 111, 14279.
16 J.-Q. Goh, S. Malola, H. Häkkinen and J. Akola, J. Phys. Chem. C, 2013, 117, 22079.

17 T. Iwasa and K. Nobusada, and A. Nakajima, J. Phys. Chem. C, 2013, 117, 24586.

18 O. Lopez-Acevedo, H. Tsunoyama, T. Tsukuda, H. Häkkinen and C. M. Aikens, J. Am. Chem. Soc., 2010, 132, 8210.

19 D. M. P. Mingos, Dalton Trans., 2015, 44, 6680.

20 S. Antonello, N. V. Perera, M. Ruzzi, J. A. Gascón and F. Maran, J. Am. Chem. Soc., 2013, 135, 15585.

21 D. Jiang, M. Kühn, Q. Tang and F. Weigend, J. Phys. Chem. Lett., 2014, 5, 3286.

22 A. B. Cornford, D. C. Frost, C. A. McDowell, J. L. Ragle and I. A. Stenhouse, J. Chem. Phys., 1971, 54, 2651.

23 N. L. Ma, W.-K. Li and C. Y. Ng, J. Chem. Phys., 1993, 99, 3617.

24 K. Kwak, Q. Tang, M. Kim, D. Jiang and D. Lee, J. Am. Chem. Soc., 2015, 137, 10833.

25 H. Qian, Y. Zhu and R. Jin, ACS Nano, 2009, 3, 3795.

26 S. Y. Park and D. Lee, Langmuir, 2012, 28, 7049.

27 A. L. Ankudinov, B. Ravel, J. J. Rehr and S. D. Conradson, Phys. Rev. B: Condens. Matter Mater. Phys., 1998, 58, 7565.

28 J. Enkovaara, C. Rostgaard, J. J. Mortensen, J. Chen, M. Dułak, L. Ferrighi, J. Gavnholt, C. Glinsvad, V. Haikola, H. A. Hansen, H. H. Kristoffersen, M. Kuisma, A. H. Larsen, L. Lehtovaara, M. Ljungberg, O. Lopez-Acevedo, P. G. Moses, J. Ojanen, T. Olsen, V. Petzold, N. A. Romero, J. StausholmMøller, M. Strange, G. A. Tritsaris, M. Vanin, M. Walter, B. Hammer, H. Häkkinen, G. K. H. Madsen, R. M. Nieminen, J. K. Nørskov, M. Puska, T. T. Rantala, J. Schiøtz, K. S. Thygesen and K. W. Jacobsen, J. Phys.: Condes. Matter, 2010, 22, 253202.

29 M. Walter, H. Häkkinen, L. Lehtovaara, M. Puska J. Enkovaara, C. Rostgaard and J. J. Mortensen, J. Chem. Phys., 2008, 128, 244101.

30 J. P. Perdew, K. Burke and M. Ernzerhof, Phys. Rev. Lett., 1996, 77, 3865.

31 N. K. Chaki, Y. Negishi, H. Tsunoyama, Y. Shichibu and T. Tsukuda, J. Am. Chem. Soc., 2008, 130, 8608.

32 O. Toikkanen, V. Ruiz, G. Rönnholm, N. Kalkkinen, P. Liljeroth and B. M. Quinn, J. Am. Chem. Soc., 2008, 130, 11049.

33 M. Hesari, M. S. Workentin and Z. Ding, ACS Nano, 2014, 8, 8543 .

34 K. Konishi, Struct. Bonding, 2014, 161, 49.

35 S. Yamazoe, S. Takano, W. Kurashige, T. Yokoyama, K. Nitta, Y. Negishi and T. Tsukuda, Nat. Commun., 2016, 7, 10414.

36 M. S. Devadas, V. D. Thanthirige, S. Bairu, E. Sinn and G. Ramakrishna, J. Phys. Chem. C, 2013, 117, 23155.

37 J. Nishigaki, S. Yamazoe, S. Kohara, A. Fujiwara, W. Kurashige, Y. Negishi and T. Tsukuda, Chem. Commun., 2014, 50, 839.

38 Y. Negishi, N. K. Chaki, Y. Shichibu, R. L. Whetten and T. Tsukuda, J. Am. Chem. Soc., 2007, 129, 11322.

39 D. Lee, R. L. Donkers, J. M. DeSimone and R. W. Murray, J. Am. Chem. Soc., 2003, 125, 1182.

40 Y. Kamei, N. Robertson, Y. Shichibu and K. Konishi, J. Phys. Chem. C, 2015, 119, 10995. 